\title{
Acute Myocardial Infarction in Patient with Mitral Stenosis: A Rare Case
}

\section{Niniek Purwaningtyas*}

Faculty of Medicine, Department of Cardiology and Vascular Medicine, University of Sebelas Maret, Moewardi Hospital, Surakarta, Jawa Tengah (Central Java), Indonesia

\begin{abstract}
Background: ST Elevation Myocardial Infarction (STEMI) is one type of acute myocardial infarction (AMI) which is rarely found as a complication of mitral stenosis (MS). STEMI which underlies by severe MS cases and coexisted with atrial fibrillation (AF) and thrombus are rarely encountered in the literature and in daily practice. When we are confronted with STEMI followed by AF, we often think that AF occurs as a complication of STEMI, making the co-existence of a heart valve disease such as MS often underestimated. In a literature it was also mentioned that the existence of MS usually just being thought by physician after re-examination. The introduction of these cases requires careful accuracy on history taking, physical examination and diagnosis establishment to get optimal treatment for patients.
\end{abstract}

Objective: Presenting the case of MS followed by Inferior STEMI and discusses the patho-physiology.

Case illustration: A-51-year-old man came to Dr. Moewardi General Hospital under chief complaint of chest pain since approximately 72 hours before admission, it was felt during working as a heavy pressure feeling for more than 30 minutes, Patients are referrals from Amal Sehat Hospital Wonogiri under diagnosis Inferior STEMI and has been treated for 3 days. Chest pains were followed by cold sweat. On physical examination we found blood pressure of $110 / 75 \mathrm{mmHg}$, heart rate 74 times per minute. Electrocardiography (ECG) shows AF normoventricular response of 60 times per minute, Rights axis deviation (RAD), incomplete right bundle branch block (IRBBB), pathologic $Q$ with T inversion in II, III, aVF leads, supporting STEMI Inferior figure. In the laboratory result showed elevated troponin I and Creatine Kinase-MB (CK-MB). The patient then being treated as STEMI. At Emergency Department, he was suspected for MS. After re-checked of physical examination and re-evaluation of advanced testing as ECG, chest radiography and echocardiography, we concluded that this patient has Inferior STEMI, AF, on severe MS accompanied by a thrombus in the left atrium and left atrial appendage (LAA). Patient did not use any insurance (independent-payment); therefore after treated for 7 days, the patient is discharged and planned for coronary angiography after having BPJS insurance. Patients had recurrent echocardiography at follow-up in policlinic and we obtained improvements of heart wall motion and ejection fraction (previously $40 \%$ become $52 \%$ ) and smaller thrombus in the left atrium and LAA. Coronary angiography was canceled because the patient passed away at the hospital, although he was immediately admitted to the nearest hospital.

Conclusion: The case of inferior STEMI and AF followed by thrombus in the left atrium and LAA in severe MS which is underdiagnosed before is a rare case on literature as well as in daily practice. The cause of ischemic events most likely was thrombus embolism originating from left atrial thrombus and LAA which triggered by atrial enlargement and $\mathrm{AF}$, although atherosclerosis is still possible for patient who has risk factors for coronary heart disease (CHD), such as smoking, male and aged more than 45 years old.

Keywords: ST Elevation Myocardial Infarction (STEMI); Atrial Fibrillation (AF); Mitral Stenosis (MS); Thrombus in the Left Atrium (LA); Left Atrial Appendage (LAA)

\section{Introduction}

ST Elevation Myocardial Infarction (STEMI) is the leading cause of death and disability worldwide [1]. It is known that $30 \%$ of the major causes of death include cardiovascular disease, and half of it is caused by coronary heart disease (CHD), while in Indonesia based on Riskesdas 2013 , the prevalence of CHD was $0.5 \%$ [2]. Acute coronary syndrome is an emergency condition that is characterized by symptoms of unstable chest pain, with or without changes in the ST segment and T-wave, either ST elevation, ST depression or T inversion, and with/without an increase in cardiac enzymes. Acute coronary syndrome consists of unstable angina pectoris, non-ST Elevation Myocardial Infarction (NSTEMI), and STEMI [1].

When STEMI suddenly spontaneously occur, about $90 \%$ if the etiology is mainly caused by coronary event such as plaque rupture, erosion and dissection indicating the occurrence of myocardial infarction (MI) MI type 1. MI can also cause by a condition secondary to ischemia caused by other than CHD, thus causing an imbalance between myocardial oxygen supply and demand that is called MI type 2 . In general, it was estimated that $4-7 \%$ of all patients who were diagnosed as IMA did not show any significant atherosclerotic on coronary angiography nor autopsy [3]. Mitral Stenosis (MS) is the most frequent cause of pulmonary and systemic emboli, where the presence of atrial fibrillation (AF) may increase the risk of embolic events. A few data were examined on the incidence of coronary embolism in MS patients with or without AF. The incidence of acute STEMI accompanied by MS is fairly rare cases [4].

*Corresponding author: Dr. Niniek Purwaningtyas, Faculty of Medicine Department of Cardiology and Vascular Medicine, University of Sebelas Maret Moewardi Hospital, Surakarta, Jawa Tengah (Central Java), Indonesia, Tel: +6281327301854; E-mail: dr.niniek.p@gmail.com

Received July 09, 2018; Accepted July 30, 2018; Published August 06, 2018

Citation: Purwaningtyas N (2018) Acute Myocardial Infarction in Patient with Mitral Stenosis: A Rare Case. J Cardiovasc Dis Diagn 6: 333. doi: 10.4172/23299517.1000333

Copyright: (c) 2018 Purwaningtyas N. This is an open-access article distributed under the terms of the Creative Commons Attribution License, which permits unrestricted use, distribution, and reproduction in any medium, provided the original author and source are credited. 


\section{Case Illustration}

\section{Identity of the patient}

$\begin{array}{ll}\text { Name } & : \text { Mr. M } \\ \text { Age } & : \text { 51 year-old } \\ \text { Sex } & : \text { Male } \\ \text { Religion } & : \text { Islam } \\ \text { Occupation } & : \text { Private employee } \\ \text { Address } & : \text { Jatiroto, Wonogiri } \\ \text { MR number } & : \text { 01352155 } \\ \text { Billing source } & : \text { Independent } \\ \text { Admission Date } & : \text { September 7- 14, 2016 }\end{array}$

\section{Case Report}

A 51-year-old man was referred from Amal Sehat Hospital, Wonogiri On September 7 2016, under diagnosis Inferior STEMI. Patients have been treated for 3 days and he got therapy such as: oral ISDN $3 \times 5 \mathrm{mg}$, oral clopidogrel $1 \times 75 \mathrm{mg}$, oral tromboaspilet $1 \times 80$ $\mathrm{mg}$, subcutaneous injection (SK) fondaparinux $2.5 \mathrm{mg}$ and intravenous injection (IV) ketorolac $3 \times 30 \mathrm{mg}$. Patients were referred to Dr. Moewardi General Hospital by family's request.

Patients complain for chest pain since approximately 72 hours before admission when patient is at work. Chest pain is felt like a heavy pressure on chest for more than 30 minutes and not relieved by having rest. Pain does not expand to the left hand and back. Complaints were accompanied by a cold sweat. Nausea and vomiting were not present. Patients never complained for chest pain before.

Patient denied for having shortness of breath and chest palpitation before. Patients used to sleep with one pillow. Shortness of breath however while activity was denied. Patients never complain of sudden woke up at night because of breathlessness. No fever and cough. Urination and defecation was normal.

A previous history of hypertension and diabetes mellitus was denied. The patient had no previous history of heart disease. Patient has a history of smoking since 20 years ago and still continued. Patients used to smoke 20 cigarettes per day. The patient had no history of alcoholic drinking. Patients did not know whether he has history of high cholesterol or not, because the patient never check it before. History of heart attack at young age from his parents was denied. Patient said that at the age of 11 years, he had experienced a fever, sore throat and joints pain but did not go to the doctor, and only took herbal drink.

Examination of vital signs showed that blood pressure was 110/75 $\mathrm{mm} \mathrm{Hg}$, pulse frequency were 62 beats per minute, heart rate were 74 beats per minute with an irregular rhythm, respiratory rate were 20 times per minute with $98 \%$ oxygen saturation using 3 liters of oxygen per minute via nasal cannula. No jaundice and anemic on eye examination. The jugular venous pressure was not increased.

On examination of the chest we obtained symmetrical shape, no chest wall retraction. On cardiac physical examination we found that ictus cardiac were invisible. Ictus cardiac were palpable in dominance at intercostal spatium V linea midklavikularis. On heart percussion we found no enlarged cardiac, on auscultation of heart we found the $1^{\text {st }}$ and $2^{\text {nd }}$ cardiac sound with irregular rhytm, and we obtained diastolic murmur $2 / 4$ on apex and pan systolic murmur $3 / 6$ in $\mathrm{r}$ Left Lower Sternal Border (LLSB).
On pulmonic examination we found symmetrical chest wall movement, normal palpable fremitus, sonor percussion in both lung fields. On lung auscultation we found vesicular sound with no rales and wheezing.

On abdominal examination we found that abdominal wall were comparable to the chest wall, normal bowel sounds and no tenderness. On the upper and lower extremities we found warm extremities and no edema (Figure 1).

The results of an EKG on September 62016 from Amal Sehat Hospital, Wonogiri we found an AF rhythm with heart rate of 60 beats per minute, right axis deviation (RAD), QRS duration of 0:08 seconds, incomplete right bundle branc block (IRBBB), Q pathologic accompanied by slight elevated ST segment $<1 \mathrm{~mm}$ along with $\mathrm{T}$ inversion in II, III, aVF leads supporting Inferior STEMI features.

The results of an EKG on September 72016 in ER RSDM we obtained AF rhythm with heart rate 70 beats per minute, right axis deviation (RAD), QRS duration 0:08 seconds, incomplete right bundle branch block (IRBBB), Q pathologic accompanied by slight elevated ST segment $<1 \mathrm{~mm}$ along with T inversion in II, III, aVF lead. On the right and posterior ventricle we found no ST segment elevation. It supports Inferior STEMI features.

The results of an EKG on September 82016 showed AF rhythm with heart rate of 90 beats per minute, right axis deviation (RAD), QRS duration of 0.08 seconds, incomplete right bundle branch block (IRBBB), Q pathologic and slight increased ST segment $<1 \mathrm{~mm}$ accompanied with $\mathrm{T}$ inversion in II, III, aVF lead, it support Inferior STEMI features (Figures 2-4).

On chest X-ray examination, it was shown Posteroanterior (PA) figure, asymmetric, quite fair inspiration, Cardio Thorax Ratio (CTR)

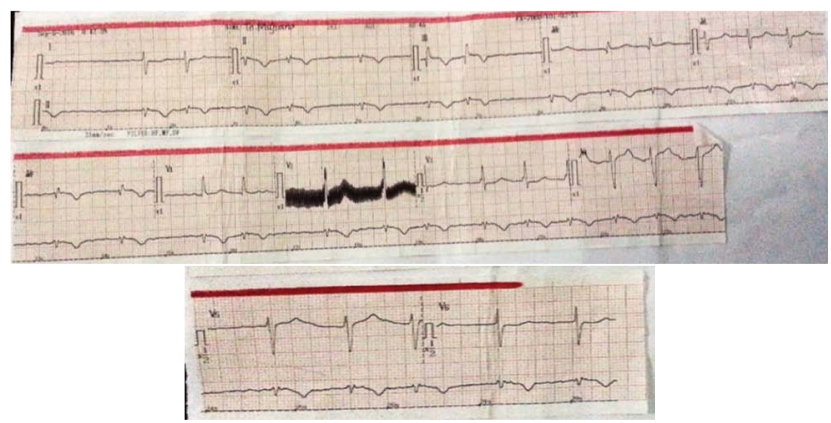

Figure 1: EKG on September 6, 2016 at Amal Sehat Hospital, Saradan, Indonesia.

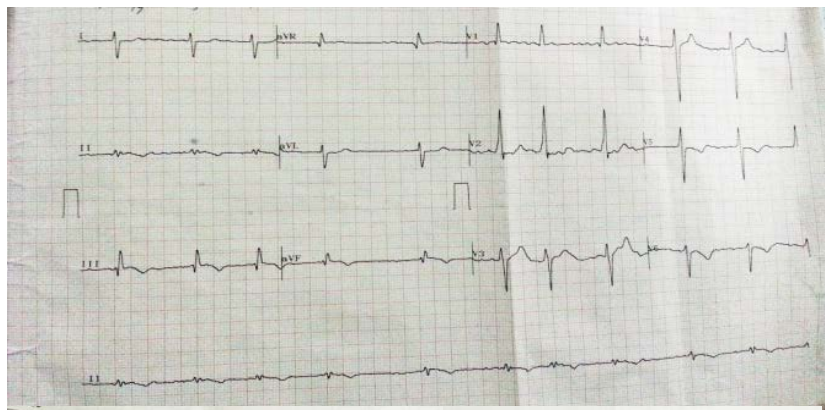

Figure 2: EKG on September 7, 2016 (ER at Dr Moewardi General Hospital, Surakarta, Indonesia). 
Citation: Purwaningtyas N (2018) Acute Myocardial Infarction in Patient with Mitral Stenosis: A Rare Case. J Cardiovasc Dis Diagn 6: 333. doi: 10.4172/2329-9517.1000333

Page 3 of 5

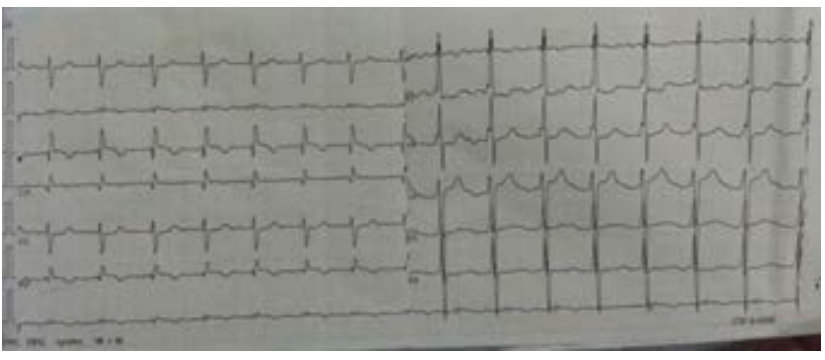

Figure 3: EKG on September 8, 2016 (on ICVCU).

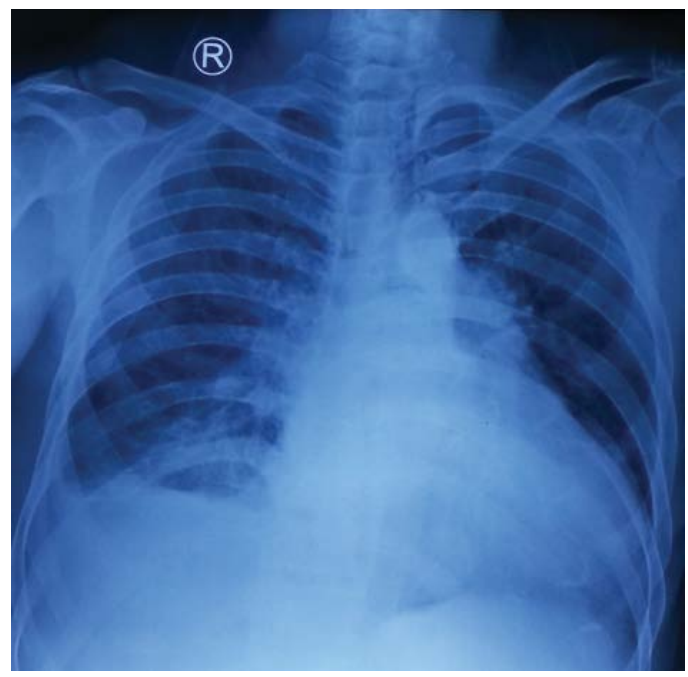

Figure 4: Postero-anterior (PA) Chest radiography on September 7, 2016

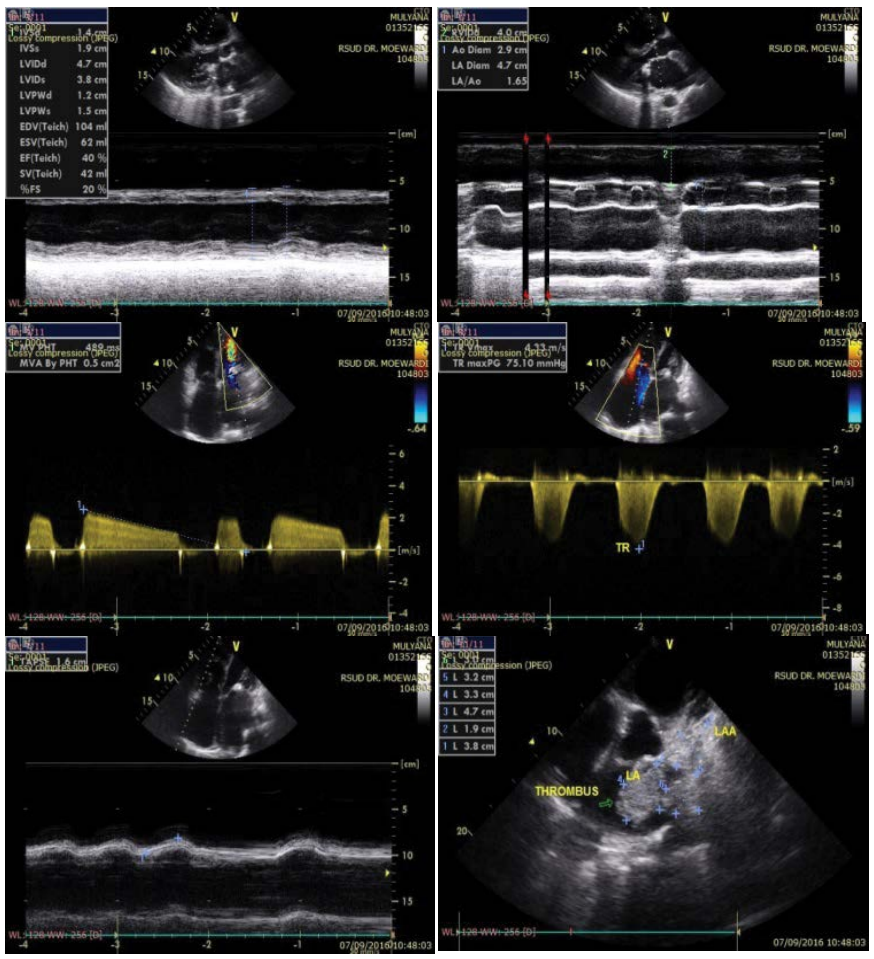

Figure 5: Echocardiography finding (September 7, 2016).
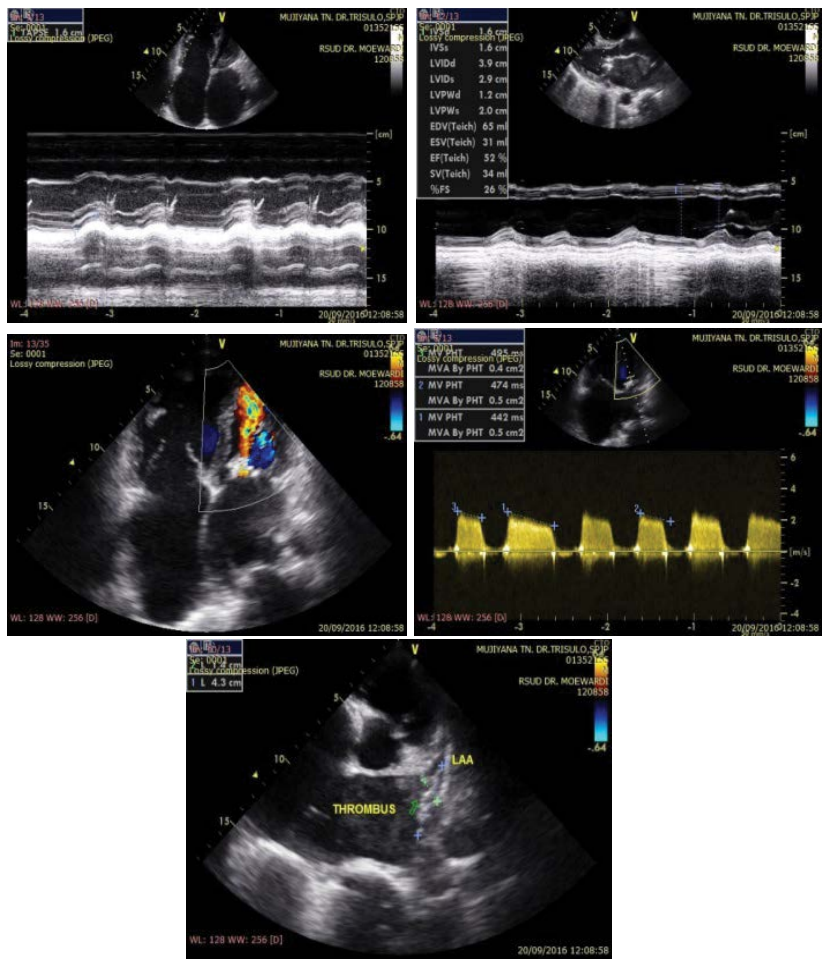

Figure 6: Echocardiogrphy finding on September 20, 2016.

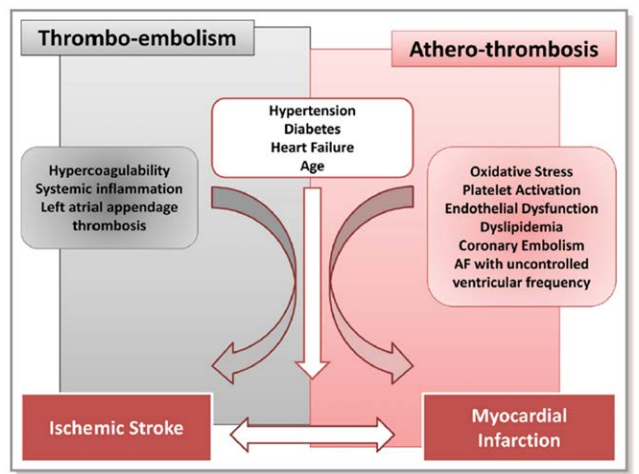

Figure 7: Thromboembolism and athero-thrombotic mechanism on AF.

of $60 \%$, cardiac waist disappeared, and the apex was lifted, without signs of pulmonary congestion. The impression of this radiography was cardiomegaly with the configuration of Left Atrial Hypertrophy (LAH) and Right ventricle hypertrophy (RVH).

In laboratory studies we found an increase in troponin I and Creatine Kinase-MB (CK-MB) where troponin I was $5.73 \mathrm{u} / \mathrm{L}$ and CK$\mathrm{MB}$ was $12.74 \mathrm{u} / \mathrm{L}$ (Table 1 and Figure 5).

The echocardiography on September 7, 2016 showed Left Ventricular Hypertrophy (LVH) concentric with IVSd of $14 \mathrm{~mm}$, Posterior Wall Diameter (PWD) of $12 \mathrm{~mm}$, and Left Ventricular Internal Diameter End Diastole (LVIDd) of $47 \mathrm{~mm}$. systolic function of left ventricular was decreased, fraction ejection $40 \%$. Right heart chamber dimensions were enlarged, moderate tricuspid regurgitation with PG $75.10 \mathrm{mmHg}$, we found mitral valve stenosis with Mitral Valve Area (MVA) by Pressure Half Time (PHT) of $0.5 \mathrm{~cm}^{2}$ and kinetic 


\begin{tabular}{|c|c|c|c|}
\hline Indicator & Result & Unit & Referral \\
\hline Hemoglobine & 14.3 & $\mathrm{~g} / \mathrm{dl}$ & $12.0-15.6$ \\
\hline Hematocrite & 43 & $\%$ & $33-45$ \\
\hline Leucocyte & 7.9 & Ribu/ $\mathrm{ll}$ & $4.5-11.0$ \\
\hline Thrombocyte & 118 & Ribu/ $\mu \mathrm{l}$ & $150-450$ \\
\hline Erythrocyte & 4.61 & $\mathrm{Juta} / \mathrm{\mu l}$ & $4.10-5.10$ \\
\hline Blood Sugar & 112 & $\mathrm{mg} / \mathrm{dl}$ & $60-140$ \\
\hline SGOT & 137 & $\mathrm{u} / \mathrm{l}$ & $<31$ \\
\hline SGPT & 77 & $\mathrm{u} / \mathrm{l}$ & $<34$ \\
\hline Albumin & 3.9 & $\mathrm{~g} / \mathrm{dl}$ & $3.5-5.2$ \\
\hline Creatinine & 2.3 & $\mathrm{mg} / \mathrm{dl}$ & $0.6-1.1$ \\
\hline Urea & 53 & $\mathrm{mg} / \mathrm{dl}$ & $<50$ \\
\hline Sodium & 128 & $\mathrm{ro} / \mathrm{L}$ & $136-145$ \\
\hline Potassium & 3.8 & $\mathrm{ro} / \mathrm{L}$ & $3.3-5.1$ \\
\hline Chloride & 96 & $\mathrm{ro} / \mathrm{L}$ & $98-106$ \\
\hline HbsAg & Non-reactive & -- & -- \\
\hline Troponin I & 5.73 & $<0.5$ & -- \\
\hline CK-MB & 12.74 & $<4.9$ & -- \\
\hline Anti HCV & Non-reactive & -- & -- \\
\hline Uric acid & 7.7 & $\mathrm{mg} / \mathrm{dl}$ & $2.4-6.1$ \\
\hline Total Cholesterol & 150 & $\mathrm{mg} / \mathrm{dl}$ & $50-200$ \\
\hline LDL Cholesterol & 116 & $\mathrm{mg} / \mathrm{dl}$ & $70-156$ \\
\hline HDL Cholesterol & 39 & $\mathrm{mg} / \mathrm{dl}$ & $36-77$ \\
\hline Triglycerids & 63 & $\mathrm{mg} / \mathrm{dl}$ & $<150$ \\
\hline PT & 15 & Detik & $10.0-15.0$ \\
\hline APTT & 34.8 & Detik & $20.0-40.0$ \\
\hline INR & 1.250 & -- & -- \\
\hline $\begin{array}{l}\text { Report Conclusions: } \text { Elevated cardiac enzymes, Elevated transaminase enzyme, } \\
\text { Azotemia }\end{array}$ & & & \\
\hline
\end{tabular}

Table 1: Laboratory findings.

\begin{tabular}{|l|}
\hline AF \\
\hline Cardiac surgery \\
\hline Coronary Atherosclerosis \\
\hline Dilatation cardiomyopathy \\
\hline $\begin{array}{l}\text { Emboli by Tumor/Thrombus through Patent Foramen Ovale (PFO)/Atrial Septal } \\
\text { Defect (ASD) }\end{array}$ \\
\hline latrogenic Emboli (Intervention Procedure) \\
\hline Left Ventricle Aneurism \\
\hline Non -Infected Thrombi on Prosthetic valve \\
\hline Septic Emboli from infective Endocarditis \\
\hline Tumor (myxoma atrium, papillary fibroelastoma) \\
\hline Cardiac Valve Disease \\
\hline
\end{tabular}

Table 2: The causes of coronary embolism according to Camaro dan Aengevaeren in 2009.

impair on wall motion in the inferior. Right ventricular function was decreased with tricuspid Annular Plane Systolic Excursion (TAPSE) of $16 \mathrm{~mm}$. There was thrombus in the left atrium of $4.7 \times 3.3 \mathrm{~cm}$ and in Left Atrial Appendage (LAA) of $1.9 \times 3.8 \mathrm{~cm}$. The impression was severe MS with LAA, moderate TR.

Patients were diagnosed by anatomical Inferior STEMI-3-days onset without fibrinolytic, severe MS with thrombus in the left atrium and LAA, tricuspid regurgitation (TR) and functional diagnosis of Killip $\mathrm{I}, \mathrm{AF}$ normo ventricular response, the etiologic diagnosis is coronary embolic suspect with differential diagnosis coronary heart disease with risk factors: Men over 45 years old, smoking as well as having score of the Thrombolysis in Myocardial Infarction (TIMI) 3/14 (moderate risk) and Global Registry of Acute Coronary Events (GRACE) score 106 (low risk) and valvular heart disease coexisted with azotemia and causes acute kidney injury (AKI) with differential diagnosis acute on chronic kidney disease (CKD), and thrombocytopenia. Because he had azotemia and thrombocytopenia, the patient were consulted to internal medicine department and was diagnosed with elevated transaminase enzyme and causes non-viral DD viral, azotemia and causes acute kidney injury (AKI) DD acute on CKD, thrombocytopenia.

The patient was admitted in the Intensive Cardio Vascular Care Unit (ICVCU) and given anticoagulants heparin 20,000 units per 24 hours and adjusted doses each day according to the results of PT/ APTT, oral aspilet $80 \mathrm{mg}$ per 24 hours, oral clopidogrel $75 \mathrm{mg}$ per 24 hours, oral simvastatin $20 \mathrm{mg}$ per 24 hours, oral bisoprolol $2.5 \mathrm{mg}$ per 24 hours, and oral warfarin $4 \mathrm{mg}$ per 24 hours at night. Patients also receive oral Curcuma $3 \times 500 \mathrm{mg}$ from internal medicine department. Patients were treated for 4 days in ICVCU then he transferred to general ward. The conditions of patients during treatment were stable and improved, chest pain gradually disappeared and he can sleep comfortably. The patient is discharged after the seventh day of treatment. Patients are encouraged to follow-up and sign up for BPJS insurance. Patients scheduled to have coronary angiography when his BPJS insurance was available. He follow-up to the clinic three days after discharged from the hospital, and he had echocardiography evaluation, it shown improvement of wall motion and ejection fraction from $40 \%$ to $52 \%$, as well as smaller thrombus (Figure 6).

\section{Discussion}

Globally, ischemic heart disease is the number one cause of death is 7 million of the 53 million deaths worldwide in 2010. Acute coronary syndrome is an acute manifestation of ischemic heart disease with 1.1 million patients in the United States and was expected were doubled in Europe. Acute myocardial Infarct with ST-segment elevation is one form of CHD which was defined as a clinical syndrome where there were typical symptoms of myocardial ischemia associated with ECG changes such as ST segment elevation and an increase in the value of biomarkers of myocardial necrosis [5].

MS is the most frequent cause of pulmonary and systemic emboli, where the presence of AF increases the risk of embolic events. Very little data is examined on the incidence of coronary embolism in MS patients with or without AF. The incidence of acute STEMI accompanied with MS is a very rare case [4] (Table 2).

LAA is an important cardiac structure with different embryology, anatomy and function. Most of the intra-cardiac thrombus is originating from the LAA during and after AF based on clinical calculation, the position of coronary ostium behind cusp valve during systolic period, protecting the coronary artery from blood flow which flowing when systolic period occur [6]. LAA is a key risk of thromboembolism associated with atrial fibrillation. At the present time, LAA is a therapeutic target for prevention of thromboembolism in patients with AF [7] (Figure 7).

The mechanism of AF-related thromboembolism can be described by Virchow's triad that includes endothelial damage, hypercoagulation states, and blood stasis, all of which resulted in the formation of a thrombus [8]. The causal link between AF and MI explained that there are same risk factor and higher inflammatory markers, of which $\mathrm{AF}$ triggers inflammation and stimulate thrombosis (AF induce inflammation) where together they will increase MI risk on future [9]. Coronary Thromboembolism followed by MI was estimated as an explanation for why AF patients have increased risk of MI [10]. 
Citation: Purwaningtyas N (2018) Acute Myocardial Infarction in Patient with Mitral Stenosis: A Rare Case. J Cardiovasc Dis Diagn 6: 333. doi: 10.4172/2329-9517.1000333

Page 5 of 5

Left atrial thrombus and LAA usually consists of red blood cells and fibrin, which is typical of the slow venous flow conditions as well, as it was recommended to use oral anticoagulation for the prevention of stroke in patients with AF [11]. Histological examination of the research by Shibata et al. toward samples of thrombus were successfully aspirated from the coronary showed a fresh red thrombus, this aspiration is very important in suppressing the occurrence of thromboembolic event which potentially causes IMA even in the absence of atherosclerosis, ie on 28 out of 29 patients in the coronary embolism group due to AF who will have percutaneous coronary intervention (PCI). These red thrombi have clinical significance after primary PCI thrombus aspiration analysis STEMI who showed that the red thrombus has a large volume and associated with increased 30-daysmortality when compared to the white thrombus consisting primarily of fibrin and red platelet. Red thrombus which formed due AF becomes very dangerous in patients with STEMI [12]. In this case, the patient showed stable condition during hospital stay. Although at the time of patients follow-up to the clinic and performed echocardiography has shown improvement of kinetic wall motion, increase on ejection fraction, and smaller size of the thrombus and have a good condition without any significant complaints, however, later reported that the patients were reported to have sudden unconsciousness. Patients could not be saved although his family has brought the patient to the nearest hospital. STEMI, AF, severe MS accompanied by a thrombus in the left atrium or LAA provides an overview of clinical implications and a poor prognosis [13-15].

\section{Conclusion}

We present the case of STEMI with AF at which at time of referral, the previous diagnosis did not know any severe MS followed by thrombus in the left atrium and LAA. This case is rare both in literature and in daily practice. The most cause of ischemic events are likely embolic thrombus originating from left atrial thrombus triggered by enlarged atrium and AF, although it is still possible for atherosclerosis factors as a cause of STEMI based on the risk factors on the pasien. Accurate anamnesis, thorough physical examination and evaluation of investigations results are very important on deciding diagnosis and optimal management of these patients.

\section{References}

1. Thygesen K, Alpert JS, Jaffe AS, Simoons ML, Chaitman BR, et al. (2012) Third universal definition of myocardial infarction. Circulation 126: 2020-2035.

2. Health Research and Development Agency of the Ministry of Health of the Republic of Indonesia (2013) Basic Health Research Riskesdas 2013. Ministry of Health Republic of Indonesia. pp: 88-91.

3. Kolodgie FD, Virmani R, Finn AV, Romero ME (2015) Embolic myocardial infarction as a consequence of atrial fibrillation. Circulation 132: 223-226.

4. Cardoz J, Jayaprakash K, George R (2015) Mitral stenosis and acute ST elevation myocardial infarction. Proc (Bayl Univ Med Cent) 28: 207-209.

5. O'gara, PT, Kushner, FG, Ascheim DD, Casey DE Jr, Chung MK, et al. (2013) ACCF/AHA Guideline For The Management of ST-Elevation Myocardia Infarction: A Report of The American College of Cardiology Foundation American Heart Association Task Force on Practice Guidelines. Circulation 127: e362-425.

6. Hara H, Virmani R, Holmes DR Jr., Buchbinder M, Lesser JR, et al. (2009) Is the left atrial appendage more than a simple appendage? Catheter Cardiovasc Interv 74: 234-242.

7. Regazzoli D, Ancona F, Trevisi N, Guarracini F, Radinovic A, et al. (2015) Left atrial appendage: Physiology, pathology, and role as a therapeutic target. BioMed Research International. pp: 2-3.

8. Henriques JP, Zijlstra F, Ottervanger JP, De Boer MJ, Hof Van't AWJ, et al (2002) Incidence and clinical significance of distal embolization during primary angioplasty for acute myocardial infarction. Eur Heart J 23: 1112-1117.

9. Iwasaki YK, Nishida K, Kato T, Nattel S (2011) Atrial fibrillation pathophysiology: Implications for management. Circulation 124: 2264-2274.

10. Soliman EZ, Safford MM, Muntner P, Khodneva Y, Dawood FZ, et al. (2014) Atrial fibrillation and the risk of myocardial infarction. JAMA Intern Med 174 107-114.

11. Nattel S, Opie LH (2006) Controversies in atrial fibrillation. Lancet $367: 262-272$.

12. Quadros AS, Cambruzzi E, Sebben J, David RB, Abelin A, et al. (2012) Red versuswhite thrombi in patients with ST-Elevation myocardial infarction undergoing primary percutaneous coronary intervention: Clinical and angiographic outcomes. Am Heart J 164: 553-560.

13. Camaro C, Aengevaeren WRM (2009) Acute myocardial infarction due to coronary artery embolism in a patient with atrial fibrillation. Netherland Heart Journal 17: 297-299.

14. Fuster V, Walsh RA, Harrington RA (2011) Pathophysiology of heart failure. In: Hurst the Heart (13th edn). New York: McGraw-Hill, USA. pp: 2738-2812.

15. Violi F, Soliman EZ, Pignatelli P, Pastori D (2016) Atrial fibrillation and myocardial infarction: A systematic review and appraisal of pathophysiologic mechanisms. J Am Heart Assoc 5: e003347. 